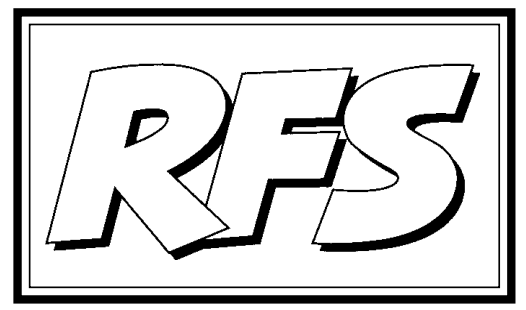

Revista de Fomento Social, 55 (2000), 85-104

\title{
La minusvalía psíquica: implicaciones éticas
}

\section{Eduardo LÓPEZAZPITARTE*}

Meimpresionó el recuerdo que una persona, cercana alos 40 años, guardaba de su infancia. Con cierta frecuencia solía repetirle a su madre: «mamá, yo soy buena, pero no soy feliz». Es una expresión simbólica de lo que para muchos significa todavía la moral. Un código deleyes, normas, obligaciones, preceptos, exigencias y mandatos, que podrán servir para hacernos mejores, pero con un precio excesivamente elevado: Ia renuncia a la felicidad. Una visión que para la persona normal sehace bastante insoportabley que, cuando se intenta aplicar sobre sujetos con determinadas deficiencias psíquicas, parece todavía más injusta einaceptable.

Por eso, en estas ocasiones, me gusta insistir en las raíces más primitivas y etimológicas del término moral, como una urgencia que nace de nuestras propias estructuras antropológicas. Toda preocupación ética brota de un sentimiento profundo de insatisfacción. No estamos satisfechos con los mecanismos impulsivos ofrecidos por la naturaleza, que buscan simplemente la satisfacción inmediata, sometidos al principio del placer, sino que deseamos

\footnotetext{
Catedrático de Teología Moral. Facultad de Teología. Granada.
} 
darle una configuración, compensados por el principio de realidad, para orientarlos haciaun proyecto humanizante. En estesentido, la moral no es nada más que el estilo de vida concreto que cada persona desea darle a su propia existencia ${ }^{1}$, como el artista modela una obra de artesanía con los materiales informes quelehan sido dados. El simplehecho deabandonarsea las pulsiones naturales no es ninguna garantía para el desarrollo y maduración del ser humano. En función de ese destino por el que cada persona opte, tendrá que seguir un itinerario concreto que lo conduzca haciala meta el egida. El valor ético sería, entonces, la invitación silenciosa que ilumina los caminos de nuestra propia autorrealización. Es una voz que parecevenir desde fuera, pero queno es sino el eco y la consecuencia de la opción que cada persona toma en su interior.

Para el descubrimiento de estos valores éticos, la moral no es una ciencia autónoma e independiente, como si pudieran deducirse de una simple reflexión abstracta, sin ningún contacto con la realidad. Lo que humaniza de verdad a la persona exige un estudio interdisciplinar, para recoger los datos de las diferentes ciencias, $y$, desde una perspectiva más totalizante, ofrecer lo que parece más de acuerdo con su dignidad. Por eso, las mismas exigencias psicológicas, jurídicas y hasta políticas, pueden llegar a convertirseen auténticas obligacioneséticas.

Plantear los aspectos éticos de la minusvalía psíquica es señalar, por tanto, aquellos espacios donde no podemos sentirnos satisfechos en nuestra relación con tales personas, o queellas mismas deberían tener presentes, dentro desus posibilidades, parasu propia autorrealización. El bajo nivel desu funcionamiento intelectual, significativamenteinferior a lamedia, con todas las connotaciones que ello implica, obliga a que cualquier reflexión sobre este hecho tenga en cuentas sus características peculiares ${ }^{2}$. Al hablar de la dimensión ética, me voy a fijar con brevedad en aquellas lagunas que las ciencias detectan y que

1 Para una ampliación de estos aspectos puede verse E. López Azpitarte, Fundamentación de la ética cristiana, San Pablo, Madrid 1994, 45-150. Esta falta de proyecto existencial es lo que motiva el carácter depresivo de nuestra sociedad postmoderna. Cf., por ejemplo, J. L. del Barco, Del ocaso de la modernidad a la sensibilidad postmoderna, Pensamiento 49 (1993) 201-216. P. Gilbert, La crise du sens, Nouvelle Révue Théologique 116 (1994) 76-93. T. Anatrella, Contra la sociedad depresiva, Sal Terrae, Santander 1995. I. Prigent, Dépression, sens, signification, Lumière et Vie no 228 (1996) 7-16.

2 Cf. A. Fierro, La deficiencia mental desde el punto de vista psicológico, en AA.VV., Matrimonio y deficiencia mental, Universidad Comillas, Madrid 1997, 73-89. También, L. Herrero, Los enfermos mentales, quiénes son, cuántos, dónde están, qué necesitan, Labor Hospitalaria 27 (1995) 299-302. 
fundamentan nuestras obligaciones éticas. En una primera parte, haréreferencia a las exigencias más generales que tod os tenemos hacia un colectivo como éste, para centrarmea continuación en al gunos puntos concretos que afectan, más particularmente, a estas personas y a su entorno.

\section{Exigencias básicas y generales}

\subsection{Superar el rechazo de lo diferente}

La psicología nos recuerda que, sobre todo a nivel inconsciente, lo que es distinto amenaza de inmediato nuestra seguridad. Al romper con nuestros esquemas habituales o no encajar dentro de nuestras costumbres adquiridas, sevivencia como al go peligroso que pone en peligro la tranquilidad conseguida, que desafía los planteamientos tradicionales, que desestabiliza la armonía alcanzada, después de muchos esfuerzos. Es el mismo fenómeno queacontece con todo lo nuevo cuando, con su originalidad inédita, conmociona el orden establecido. No resulta extraño, por tanto, que los mecanismos de defensa actúen contra estos elementos difíciles deintegrar ${ }^{3}$. El rechazo o la marginación son los caminos más frecuentes para evitar una presencia que molesta. La historia estállena de acontecimientos que, en el ámbito social, político, cultural o religioso, demuestran esta exclusión, con la violencia inherente a cualquier forma de fanatismo.

Y no cabe duda que las personas con minusvalías psíquicas, por el hecho de no encajar dentro de nuestros criterios de normalidad, están dentro de esa lista de marginados a los que la sociedad pretende, por lo menos, ignorar, cuando ya no es posiblesu destrucción. Son muchos los que niegan una espacio para existir a todos aquellos que no hayan superad o el nivel de lo que hoy se designa como calidad de vida. El simplehecho de vivir no parece digno ni apetecible, si no va acompañado de otra serie de cualidades y exigencias que lo hagan justificable. Y como la posibilidad de una vida mejor irá progresivamente aumentando, el nivel mínimo para la existencia se pondrá cada vez más alto. La eutanasia neonatal es una práctica que hoy se acepta sin mayor dificultad en bastantes Centros hospitalarios. Como el diagnóstico previo, queaconsejarala interrupción anterior del embarazo, no sería suficienteen todos los casos, este

3 A. Mineau, I'agression: du biologique au politique, Laval Théologique et Philosophique 42 (1992) 215-224. V. Elizondo, Análisis del racismo, Concilium no 248 (1993) 81-90. F. Chispar, La violence dans lexpérience humaine: la fragilité et la puissance, Lumière et Vie $n=236$ (1996) 7-18. 
método se convertiría en la barrera infranqueable para impedir la existencia a personas con cualquier tipo de patología. Las estadísticas demuestran queuna mayoría dela población juzga aceptable el aborto voluntario cuand o se descubre la presencia de un feto anormal ${ }^{4}$, ¿por qué no hacer lo mismo un poco tiempo después, si antes no se pudo obtener esteconocimiento? La aplicación de la eutanasia, en el momento de nacer, tendría menos complicaciones jurídicas y no despertaría tantas dificultades emotivas, al tratarsede un ser que apenas comienza su existencia.

Semejante criterio, tan ampliamente difundido, no es sólo un atentad o contra la vida que ya existe-aquí nadiepodrádudar, apoyándoseen otras teorías sobre el comienzo dela vida, que nos encontramos frente a un ser humano-, sino que se convierte también en una acusación terrible y explícita contra todas las personas deficientes que nos rodean, y a las que manifestamos con esa conducta que hubiera sido mucho mejor su eliminación, porque no parece digna una existencia en esas condiciones. Se quiere un mundo donde no haya espacio para los más necesitados y para los que, por imperativos de la propia naturaleza, no resultan rentables ni útiles a la sociedad.

Es cierto que el lenguajeque seutiliza estálleno de otros eufemismos mucho más suaves y generosos, como si lo único que preocupara fuera la felicidad que deseamos para el otro, pero la realidad es así de simple y dramática. Aunque parezca duro, se trata de un racismo todavía más brutal, porque no sólo separamos y excluimos a los que consideramos indignos einferiores, privándoles de ciertos derechos que otorgamos a los demás, sino que les negamos de raíz el derecho más básico y fundamental a la propia existencia. La misma ecuación matemática, que ya se utiliza en al gunos centros para dejar o no morir a los recién nacidos con defectos congénitos, manifiesta la insensibilidad humana desemejanteactitud. Lacalidad potencial devida es igual ala condición actual del niño por los costes y contribución que serán exigidos a sus padres y a la sociedad ${ }^{5}$. Y habría que preguntarse muy seriamente si un mundo así, que sehace cada vez más opaco al valor dela vida para subordinarla a otros intereses que juzga superiores y más importantes, progresa y se humaniza, o no va perdiendo, a pesar de su progreso técnico, la verdadera dimensión humana. Seguimos viviendo en una sociedad donde la cultura dominante impone un

4 Puede verse lo que piensan los españoles sobre el aborto y la eutanasia en A. de Miguel, La sociedad española 1993-1994, Alianza Editorial, Madrid 1994, 244-261.

5 Es el criterio utilizado en el University of Oklahoma Health Science Center para decidir cuando se deja morir o se emplea un tratamiento terapéutico en los recién nacidos con espina bífida. Cf. la relación que aparece en Pediatrics, 72 (1983) 450-458. 
modelo en el quela inteligencia y la rentabilidad económica se presentan como valores prioritarios. Y en un mercado de valores como éste, las personas con minusvalía psíquica no se encuentran especialmente cotizadas ${ }^{6}$. Para superar este rechazo habría que recordar tres aspectos fundamentales

\subsection{Un nuevo perfil de la persona minusválida}

El primero consistiría en un esfuerzo social y colectivo para crear una actitud radicalmente distinta ante el minusválido. Como un deseo por defender la dignidad de su persona que nunca se menoscaba o deteriora, a pesar de sus componentes deficitarios. Luchar por los derechos humanos de las minorías hasid o siempreun trabajo arduo y discutido, hasta quela sociedad seabre, poco a poco, paradar espacios de convivencia a los que se consideraban marginados. Se ha dado una evolución histórica positiva desde otras épocas anteriores, cuando no había mayor sensibilidad hacia determinados grupos sociales esclavos, prisioneros, enfermos, trabajadores, mujeres, por citar algunos colectivos- hasta las Constituciones modernas que defienden la igualdad de todos los ciudadanos ${ }^{7}$. Una teoría, sin embargo, que no se aplica con frecuencia en la práctica. Todavía queda un largo camino que recorrer hasta el cumplimiento del artículo 14 de nuestra Carta Magna, que prohíbe cualquier discriminación no sólo por razón de nacimiento, raza, sexo, religión u opinión, sino por "cualquier otra condición o circunstancia personal o social", entre la que se incluye la minusvalía psíquica ${ }^{8}$. Si hasta ahora la caridad era la virtud que impulsaba a la preocupación e interés por las necesidades de estas personas, ahora es la solidaridad y la justicia quienes determinan cuál ha de ser nuestro comportamiento. Y estas obligaciones me parecen que se pueden concretar en dos puntos fundamentales.

Todavía en nuestra sociedad, el perfil de las personas minusválidas se caracteriza por sus componentes negativos. Los mismos términos que se

6 En el Noticiario J urídico de Aranzadi (4-3-1998, p. 3) se recogía una información por la que una juez de Barcelona condenaba a un ginecólogo al pago de 100 millones por no utilizar los medios necesarios para detectar una espina bífida en una gestación con riesgo, ni informar a los padres sobre la anomalía, lo que impidió un aborto voluntario.

7 Un buen estudio en G. Peces Barba, Escritos sobre derechos fundamentales, Eudema, Madrid 1988. Resumen más breve en D. Gracia, Fundamentos de Bioética, Eudema, Madrid 1989, 122-197.

8 Cf. F. C.Sáinz de Robles, Los deficientes mentales ante la ley, en AA.VV., La deficiencia mental. Aspectos médicos, humanos, legales y éticos, Universidad Pontificia de Comillas, Madrid 1992, 181-199. 
utilizan en el lenguaje común ponen de relieve aquellos aspectos que no responden al ideal de lo queseconsidera normal, como si lo substantivo de su existencia fueran justamente las limitaciones que padecen. No habría que hablar, por tanto, del mongólico, oligofrénico, deficiente o retrasado mental, sino de la persona, con toda la dignidad y riqueza que encierra, que está ciertamentecondicionada por alguna patología psíquica ${ }^{9}$. El cambio no es una cuestión puramenteterminológica; revela más bien un talante muy distinto para enfocar el problema. Ninguna deficiencia, por muy profunda que sea, destruye la dignidad deesa persona. Los derechos humanos no están condicionados por la normalidad de los sujetos, sino por el hecho de su existencia. Y si en alguna ocasión, por exigencias del bien común, la ley tuviera que limitarlos, como acontece también en los sujetos normales, ha de hacerlo con las debidas garantías jurídicas para evitar posibles abusos.

Este cambio de imagen se hace muy difícil en nuestra cultura actual, donde predomina una visión utilitaria y mercantilista, en la que no queda espacio para los grupos, como sucedecon los ancianos ${ }^{10}$, que no se valoran como rentables. Como si la economía fuese el valor por excelencia, olvidando la riqueza, al margen de su posible aportación económica ${ }^{11}$, que estas personas ofrecen a la sociedad. Son seres que, en su aparente pasividad, nos hacen descubrir la dimensión antiutilitarista del verdadero cariño y despiertan a su al rededor los sentimientos altruistas más profundos del corazón. Sólo aquellos que han vivido en contacto con estas personas saben muy bien la riqueza que encierran, a pesar de los problemas y dificultades que plantean, como también provocan conflictos aquellas que se consideran normales. Mientras no se realice este cambio deóptica, transmitiremos siempreuna seriedemensajes implícitos, que impedirán la verdadera acogida y aceptación. Si nadiepuedecaminar por la vida solitario y abandonado, pues todos necesitamos el calor de un afecto y compañía, la persona minusválida requiereuna dosis mayor decariño para compensar sus limitaciones. Además desus propias limitaciones, no hay derecho a crearles un clima delejanía y desafecto, que dificulte aún más su capacidad de relación.

9 J.R. Amor Pan, Ética y deficiencia mental, Universidad Pontificia de Comillas, Madrid 1995. J. Ma Castro, La dignidad del enfermo mental, Labor Hospitalaria 27 (1995) 308-314.

10 De ello he tratado en: Envejecer: destino y misión, San Pablo, Madrid 1999.

11 Cf. A. Pino, Integración laboral de la persona con minusvalía psíquica, en AA.VV., o. c. (n. 8), 117-137. 


\subsection{La integración en la comunidad: Más allá de las denuncias retóricas}

En segundo lugar, se requiere también un esfuerzo posterior para ver cómo es posiblesu integración en el mundo social en el que viven. Integrar, de acuerdo con el Diccionario de la Lengua, es componer un todo con sus partes; es decir, la vinculación armoniosa en el conjunto detodos sus elementos. No setrata de algo extraño, frente al que han de actuar los mecanismos de defensa, para impedir la contaminación del organismo. Es un miembro que tiene derecho a vivir en nuestro cuerpo, aunque algunas de sus funciones puedan quedar limitadas con mayor o menor profundidad. El esfuerzo de adaptación no hay que pedírselo a él, que se encuentra incapacitado para responder a todas las exigencias sociales del grupo, sino a la colectividad en su conjunto para que se haga flexible y se acomode a sus posibilidades concretas. No hay derecho a pedirles más de lo que puede darnos con todo realismo, como tampoco es bueno protegerlos de tal manera que se obstaculice la independencia y autonomía a la que podría llegar.

Todo esto significa quelas múltiples exigencias educativas, laborales, familiares y sanitarias, quelas otras ciencias ponen de manifiesto en nuestra relación con estas personas, se convierten en verdaderos imperativos éticos de los que nadie puede eximirse. El peligro, en estos casos, es que, al no sentirnos individualmente culpables de las deficiencias por recaer más en directo sobre las instituciones, nos conformemos con una simple denuncia retórica que no compromete demasiado. Un lamento que mantiene a salvo la tranquilidad de conciencia, pues se condenan y rechazan las injusticias de la situación, pero sin apenas ninguna eficacia. Es cierto que la ética privada tiene sus límites, ya que no tiene capacidad para la solución de los problemas macro sociales, pero desdeella hay querevitalizar la luchay el esfuerzo por el cambio necesario. Todo, menos entregarse impotente en manos delas estructuras, sintiénd ose vencido por las fuerzas de un destino trágico, frente al que no cabe otra postura que la aceptación fatalista.

Como recordaba J uan Pablo II, tales situaciones negativas, aun aquellas que parezcan más anónimas y complejas, "no deben inducir a nadie a disminuir la responsabilidad de los individuos, sino que quieren ser una llamada a la conciencia de todos para que cada uno tome su responsabilidad, con el fin de cambiar seria y valientemente esas nefastas realidades y situaciones intolera-

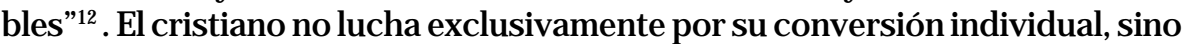

12 Juan Pablo II, Exhortación apostólica sobre la reconciliación y penitencia, no 16, Mundo cristiano, Madrid 1985, p. 43. Sobre este tema puede consultarse E. López Azpitarte, El tema 
que se enfrenta también contra las estructuras, orden, ambiente einstituciones -sean quienes sean los culpables- que no reconocen los verdaderos valores humanos. Es un esfuerzo para empeñarse "con sabiduría en el mejoramiento o en la transformación de la sociedad según las exigencias y posibilidades del momento histórico"13. El que hoy se creyera exento de este compromiso social, para refugiarse en la interioridad de su ética, quedaría prisionero de su ingenuidad o de su egoísmo. Una tarea ineludible que nace de la responsabilidad política de cada ciudadano. A veces, da pena contemplar la falta decolaboración con aquellas familias o instituciones que trabajan por el cumplimiento de estos derechos fundamentales. El mundo de nuestras omisiones y apatías es demasiado amplio como para quedarse satisfecho y con las manos limpias.

\subsection{Un tratamiento global y totalizante}

Existe una tercera obligación ética que conviene subrayar con especial énfasis en estos casos. Toda enfermedad, sobre todo cuando no es algo levey pasajero, revela la vulnerabilidad de la carneque no había provocado hasta el momento ningún tipo de protesta. Si la salud es el silencio pacífico del organismo, podríamos definir a la enfermedad como el grito del cuerpo que se siente amenazado no sólo por el desorden de su biología, sino por todo el mundo simbólico que despierta y que afecta también, mucho más de lo que a veces creemos, a toda la psicología del individuo. Es una experiencia de la finitud y de la impotencia que despoja a las personas de su propia seguridad ${ }^{14}$. Cualquiera que se acerque un poco al interior de un enfermo lo primero que descubre es una cierta angustia escondida que, a veces, no se puede casi explicitar o se manifiesta de forma indirecta y simbólica. Es el fruto, en el fondo, de una inseguridad que afecta más o menos profundamente según las diversas situaciones objetivas y personales, pero queacompañasiempreacualquier síntoma patológico.

La misma Asociación Internacional para el Estudio del Dolor, aunque insiste con exceso en su carácter orgánico, no olvida la desagradable experiencia emocional que siempre se le asocia y la inevitable interpretación subjetiva de cada persona. Es decir, hasta una sensación de origen biológico tieneenormes

del pecado en la «Reconciliación y Penitencia» de J uan Pablo II, Proyección, 33 (1986) 5569. Con mayor amplitud en o. c. (n. 1), 428-449.

$13 \mathrm{lb}, 42$

14 Cf. A. Vannesse, Ce qu'être malade veut dire y $\mathrm{Cl}$. Geet, La maladie comme expérience et comme condition, Supplément no 184 (1993) 21-32 y 33-55. 
resonancias en el mundo afectivo y emocional, que no siempre se tienen en cuenta ${ }^{15}$. La medicina actual, que ha conseguido progresos extraordinarios con la técnica, tiene el grave peligro de la deshumanización, cuando olvida que el enfermo es ante todo un ser humano y no un simple organismo al que hay que reparar $^{16}$. La praxis tradicional buscaba curar en las ocasiones que podía; al gunas veces aliviabalos sufrimientos; pero, al menos, consolabasiempre. Hoy el progreso médico y las instituciones sanitarias han llegado a cotas muy altas de eficacia, pues sana en muchas ocasiones; mitiga los dolores casi siempre, pero apenas consuela.

Por eso, cada vez se insistemás en el aband ono de una medicinamecanicista, que busca la curación de un defecto orgánico, para implantar una terapéutica sistémica, que incluye, además, todas las otras dimensiones que responden a las necesidades psicológicas y trascendentes del enfermo. Si antes decíamos que la enfermedad es un protesta del cuerpo, su grito incluye también otras muchas demandas a las que sólo se puede responder con esa dosis de humanismo y sensibilidad, que se transmiten con el silencio comprensivo de una mirada, con el afecto deuna sonrisa, con la palabra pacientey consoladora, con la empatía que acerca a comprender la peculiaridad de cada caso ${ }^{17}$. La respuesta a esta palabra del cuerpo exige una relación mucho más global y totalizantequela simple terapia orgánica.

Si todo esto se afirma de las patologías biológicas, esta dimensión humana es aún más importante en nuestra relación con los enfermos psíquicos. Las heridas del alma son más dolorosas quelas del cuerpo y secicatrizan con mayor dificultad. Son limitaciones que afectan a lo más profundo de su personalidad y que lo hacen, por tanto, más frágil y vulnerablequea cualquier otro paciente. Desde el principio se convierten en causa de frustración parala propia familia y ambiente. Saben que no encajan en una sociedad a la que no pueden amoldarse por la incapacidad de fondo para vivir deacuerdo con los esquemas

15 O. França-Tarragó, Aspectos éticos de la asistencia al enfermo con dolor crónico, Labor Hospitalaria 27 (1995) 164-171.

16 E. López Azpitarte, Técnica y humanismo en los hospitales, Razón y Fe 235 (1997) 159-172. J. B. Linares, La atención pastoral del anciano enfermo psiquiátrico, Labor Hospitalaria 30 (1998) 114-116. R. Dasí, La atención pastoral del enfermo mental desde una visión integral e integradora de la asistencia, Labor Hospitalaria 31 (1999) 43-56.

17 E. D. Pellegrino, Las relaciones entre médicos y enfermos. Confianza y desconfianza en la ética profesional, Atlántida no 5 (1991) 44-51. AA.VV., Vivir el morir, Labor Hospitalaria no 24 (1992). B. P. Sandrin, Comprender y ayudar al enfermo, San Pablo, Madrid 1992. G. Ferrières, Voix sans visages, Études 383 (1995) 37-46. A. Brusco, Humanización de la asistencia al enfermo, Sal Terrae, Santander 1998. 
de las personas normales. Aunque logren una cierta calidad de vida con los tratamientos médicos, son conscientes de ese déficit que lo llevarán siempre como un estigma. $Y$ ante un ser como este, muchas veces nace la pena y compasión, pero que no son suficientes para aceptarlos y quererlos como merece su dignidad.

Apunto brevemente qué exigencias fundamentales se derivan por el hecho de ser persona, más allá de sus cualidades accidentales.

\section{Problemas concretos}

\subsection{Respeto a su autonomía limitada}

No existeningún respeto hacia el otro mientras no se defiende su libertad. Y el graveriesgo que existe por su condición psicológica es apoderarse también dela poca que les queda, como si fueran radicalmente incapaces de cualquier decisión. Ya Aristóteles decía que la ciencia se podía resumir en dos saberes, según la utilización que se hiciera de tales conocimientos: el saber de servicio y el saber de poder. Y la medicina posee una superioridad quecoloca al paciente a un nivel inferior, quehoy se pretende compensar con el principio de autonomía. Cuando setrata de un enfermo psiquiátrico la tentación es aún mayor, pues los conflictos entre el derecho a su autonomía y la búsqueda eficaz de su beneficencia adquieren mayor conflictividad. En cualquier enfermo, como subrayaba Freud, es casi inevitable una regresión infantil y narcisista hacia la pasividad y dependencia ${ }^{18}$. Se da un gesto de abandono e impotencia en manos dela persona o dela institución, las únicas que pueden solucionar el problema. En este sentido, la medicina ejerce una función paternal que asegura, despierta esperanzas, protege de los peligros, mantiene ilusiones, pero que también, como los propios padres, se puede aprovechar de la sumisión provocada por semejante estado para imponer su voluntad.

Si en las personas sanas no es fácil mantener el equilibrio entre ambas exigencias, más difícil aún acontece en estos casos. Su autonomía queda mermada por las limitaciones de su inteligencia, incapaz, muchas veces, de comprender y analizar los datos que se les presentan. El consentimiento informado exige una cierta madurez para su interpretación y la toma posterior de decisiones que pueden constituir un peso insoportable. La acción médica no puedeser un acto de confianza librementeentregado, pero dejar en manos del paciente la resolución de su caso también puede exceder a sus fuerzas y

18 Introducción al narcisismo, en Obras Completas, Biblioteca Nueva, Madrid 1972, vol. VI, 2022. 
posibilidades, cuando se trata, sobre todo de situaciones complejas. Y un exceso de paternalismo, con el aparente deseo de compartir y ayudar, restringiría demasiado el campo de su autonomía.

Laúnica alternativa posiblees buscar un tipo derelación en el queel médico, por una parte, no abdique de su responsabilidad y sostenga y ayude, por otra, la autonomía limitada del enfermo en esos momentos difíciles ${ }^{19}$. Un diálogo esclarecedor, donde la sensibilidad e intuición sabe interpretar los deseos, exigencias y necesidades más auténticas que no se logran expresar con claridad. A pesar de todo, no existe ningún criterio exacto que ofrezca la mejor solución. Es verdad que el paternalismo es una caricatura de la preocupación sanitaria, pero existen ocasiones en las que no puede excluirse por completo, porque mucho peor que atentar a la autonomía del paciente que se pretende asistir es dejar de curarlo. Un médico, como el evangelista Lucas en su diálogo con un fariseo, nos revela una buena regla de conducta para estas situaciones. Haciendo referencia a una pecadora pública, afirma: ¿Por eso te digo que quedan perdonados sus muchos pecados, porque ha mostrado mucho amor? Solo cuando se ama de veras al paciente podrán quedar subsanados los posibles errores desu decisión final.

\subsection{La dimensión sexual del paciente psiquiátrico}

Los recelos que todavía existen en torno al sexo aumentan aún más cuando sehace referencia al minusválido psíquico. Algunos tal vez preferirían que esta dimensión no estuviera presenteen su persona, para no tener queenfrentarse con los problemas que plantea. Las limitaciones que puedan sufrir en su psiquismo no suponen necesariamente una disminución desu libido-a veces, pudiera ser todo lo contrario-, como si se tratara de seres excepcionales que no experimentan las múltiples reacciones suscitadas por esta dimensión. La sexualidad forma parte de sus vidas, con to do el mundo de afectos, imágenes, curiosidades, sentimientos y atracciones, que a todos nos afectan. Y reprimir esta fuerza, mediantecualquiera de los mecanismos existentes, no deja de traer sus consecuencias negativas, como acontece también en las personas normales. La castidad no se manifiesta nunca en la simple continencia, sino en la integración de la fuerza pulsional. Y el minusválido,-también en este campo, como en tod os los demás- tienederecho a quese le facilite su desarrollo, dentro de sus posibilidades concretas, para no castrarlo psicológicamente en su

19 P. Verspieren, Respecter et promouvoir l'autonomie du malade, Supplément $n$ o 192 (1995) 61-68. 
afectividad y sentimientos. Yatiene otros límites, impuestos por la naturaleza, para que, además, los sometamos a otros porque nos resultan más cómodos y exigen menos preocupaciones.

Pero si no es lícito negar este dato antropológico, tampoco me parece aceptable renunciar a una tarea educativa para dejarlos abandonados en manos del instinto, como si la minusvalía-ahora, en este caso- constituyera un obstáculo infranqueable para una conducta lo más humana posible. De la misma forma que se procura educarlos para una convivencia e integración social, lo más armónica y profunda que sepueda, no veo por quéseexcluyeeste esfuerzo pedagógico en el ámbito de su sexualidad.

Comprendo muy bien que las visiones tan diferentes que hoy existen sobre la sexualidad provocan también valoraciones éticas muy distintas. Y si la tolerancia de ahora no conoce apenas límites ${ }^{20}$, parece razonable que la permisividad sea aún mayor en el caso de los minusválidos, por sus características especiales. Por eso, parto del presupuesto dequela libido humana, como cualquier otra pulsión, exige superar el nivel instintivo para vivir el sexo como lenguaje de amor, encuentro y comunión, tanto en el ámbito de la sexualidad, como en el delas relaciones estrictamentegenitales ${ }^{21}$. La educación sexual no es, en el fondo, sino capacitar al individuo para canalizar esas fuerzas y que su carácter biológico y placentero no elimine su dimensión simbólica, su expresividad amorosa, to dos sus componentes afectivos. Es decir, que no se convierta en una función puramente orgánica, marginando la riqueza humana presente, que la llena de otro significado.

Por eso, me cuesta trabajo aceptar - sin caer en un naturalismo, que yo también considero anacrónico y desfasado-que, por el simple hecho de que una conducta se aleje menos del ideal que cualquier otra, haya que darla como éticamente aceptable, sin tener en cuenta la situación concreta del individuo, sea normal o deficiente. Semejante criterio terminaría justificando acciones que no siempre estarían acreditadas por la moral, aun

20 Como simple ejemplo, en un reciente texto de educación sexual, donde se quieren cubrir los aspectos afectivo, social, sanitario, físico, ético y médico, a la pregunta: ¿Es malo hacer el amor a los 13 ó 14 años con un preservativo?, se responde: Hacer el amor con un preservativo no es malo a ninguna edad, O. Watt- S.Watt- M. Mangada, Todo lo que quieres saber sobre el sexo... y algo más. Guía informativa de 8 años en adelante. Edtorial Paraninfo, Madrid 1992, p. 179.

21 Para una ampliación de todos estos aspectos, cf. E. López Azpitarte, Ética de la sexualidad y del matrimonio, San Pablo, Madrid 1994, 11-176. También J. Vico Peinado, Liberación sexual y ética cristiana, San Pablo, Madrid 1999. 
reconociendo que una legislación determinada sólo puede defender una ética de mínimos ${ }^{22}$.

\subsection{Dificultades internas en su proceso evolutivo}

Reconocer esta urgencia educativa, también en las personas con minusvalías, no significa cerrar los ojos a otros elementos que influyen en su dinamismo sexual y que no conviene desconocer en nuestras aplicaciones prácticas. La génesis dela pulsión sexual, como primer dato, no se realiza en el momento de la adolescencia, cuando todos sus componentes se unifican, como la corriente de un río en el que desembocan otras muchos afluentes. Desde que nacemos, cada una de estas fuerzas dispersas atraviesa diferentes etapas antes de su unificación. A lo largo de este proceso primero pueden darse obstáculos que dificulten, más o menos, su posterior desarrollo. Aun la persona normal nunca está indemne de estas fisuras que condicionan después su conducta, en un grado que no siemprese podrá detectar con exactitud. Esto explica que ciertas reacciones insatisfactorias, que incluso éticamente deben catalogarse como importantes, no siempre broten de una libertad personal. Son actos más o menos compulsivos, aun sin la conciencia de esta limitación, que no sellegan a dominar por completo.

Es comprensible que estas mismas dificultades influyan, incluso con más fuerza, en el proceso evolutivo del minusválido, y aumenten después su posibilidad de integración y control. En teoría, habría que distinguir, por tanto, entre lo que nace de una verdadera libertad y lo que es producto de una responsabilidad, condicionada por otra serie de elementos y experiencias. Y lo queno se puede es medir con los mismos criterios las conductas de una persona normal -cuya valoración se hace también difícil- y los comportamientos de minusválidos que estarán aún bastante más condicionados. Incluso, determinadas expresiones, que podrían llamar la atención en otro contexto, son para ellos formas naturales y espontáneas de manifestar sus sentimientos. La objetividad de sus acciones no encierra, por tanto, el mismo significado que se encuentran en circunstancias normales. Si para la educación nunca es aconsejable, aquí habría que rechazar con más energía el empleo de la culpabilidad o de la represión con ese objetivo.

22 Cf. D. Gracia, Ética de la sexualidad, en AA.VV., o. c. (n. 2), 93-117. Sobre la relación con la ética vivil, hetratado en Moral cristiana y ética civil. Relación y posibles conflictos: Proyección 41 (1994) 305-314. Ver también E. López Azpitarte, Tolerancia e intolerancia en la Iglesia: Proyección 43 (1996) 3-13. 


\subsection{Otros factores condicionantes: Hacia una valoración personalizada}

Por otra parte, el simbolismo de la sexualidad, como hemos dicho, busca la defensa de su carácter simbólico, en el que se armonizan su función lúdica, placentera, unitiva y procreadora. Son diferentes significados que se aúnan y complementan, pero que, cuando se disocian, manifiestan una libido regresiva y todavíainfantilizada ${ }^{23}$. Si en nuestra cultura son muchos los que no captan este pluralismo de significados y se quedan exclusivamente con el que más les satisface y apetece, marginando los más importantes, tampoco debería extrañar que un minusválido no pueda comprender nada más que un determinado aspecto. También él está recibiendo de manera continua una imagen de la sexualidad, queponederelievesu dimensión hedonista y gratificante, sin insistir en sus valores más auténticos. No es fácil resistir a estos mensajes subliminales que todos recibimos, si no hay un convencimiento muy profundo que se opongan a tales influencias. Una dificultad que se hace mayor aún en las personas cuya inteligencia ha quedado disminuida. Si, además, los mismos educad ores presentan otras alternativas como dignas y aceptables, sería absurdo esperar de estas personas otro tipo de comportamientos ${ }^{24}$.

Finalmente, la valoración ética de su conducta exige otros múltiples matices que tengan en cuentan las peculiaridades de estas personas. Cuando se tiene un nivel de conocimiento valorativo y de libertad, el sujeto tiene que hacerse responsable desus actos y de sus consecuencias previstas, aunque en al gunas ocasiones no se pueda medir con exactitud el grado de culpabilidad. Los condicionantes, a veces inconscientes, actúan en el psiquismo delas personas

23 Recomiendo la lectura de T. Anatrella, El sexo olvidado, Sal Terrae, Santander 1994, donde analiza las supuestas conquistas de la revolución sexual que, al privar al sexo de su riqueza simbólica y de su contenido afectivo para convertirlo en un simpleentretenimiento placentero, ha conducido a una sexualidad infantil, vacía y disociada.

24 Algunos defienden la licitud de las mismas relaciones genitales: En consecuencia, en mi opinión, de esta divergencia de opiniones éticas no debe resultar una condena de las relaciones genitales, J. R. Amor Pan, Ética y deficiencia mental, Universidad Pontificia de Comillas, Madrid 1995, 138, y Afectividad y sexualidad en las personas con deficiencia mental, Comillas, Madrid 1997. En otra línea distinta se mueven Mạ.L. RAMÓN-LACA, Integración familiar, efectividad, sexualidad y J. GAFO, Principales problemas éticos en torno a la deficiencia mental, en AA.VV., o.c. (n.8), 81-95 y 219-238. Sobre la sexualidad del minusválido puede verse también: AA.VV., Estudios sobre la sexualidad del deficiente mental, CEFAES, Pamplona 1986. AA.VV., Afecto y sexualidad en los deficientes mentales:FEAPS, Madrid 1988. J.M. DE LAHIDALGA, A proposito de la sexualidad de los deficientes mentales: Surge 46 (1988) 293-312. M.E. GIRAULT, Educación sexual y sexualidad en la persona con discapacidad mental: Medicina y Ética 6 (1995) 213-230. B. POVEDANO, Biología de la sexualidad. La sexualidad del deficiente mental, en AA.VV., o.c. (n.2), 57-70. 
normalesy, por ello, no todo acto incorrecto se puedecatal ogar como culpable. Este hecho se hace más frecuente entre los minusválidos. El sentido de su conducta sexual no es el mismo que el de cualquier otro individuo. Un gesto exhibicionista, por ejemplo, no expresa sino un deseo de comunicación espontánea, sin las inhibiciones sociales que se imponen a los demás. Cuando las dificultades de lenguaje para relacionarseson mayores, el cuerpo seconvierte en palabra que desea el encuentro con su entorno, aunquesus manifestaciones sean poco oportunas y matizadas. El mismo fenómeno masturbatorio adquiere también otra serie de significados, añadidos a los que pueden encontrarse en la persona normal. Su menteno alcanza a descubrir por quése deben controlar ciertas exigencias corporales. Ahí busca una compensación a otras carencias quelelimitan, manifiestan su vitalidad, o expresan otras añoranzas y soledades.

Han de tenerse en cuenta la inmadurez afectiva, la fuerza de los hábitos contraídos, el estado de angustia u otros factores psíquicos o sociales que reducen, e incluso anulan la culpabilidad moral ${ }^{25}$. La moral requiere una aplicación concreta a las circunstancias personales pues, a lo largo de to do el proceso evolutivo, no se logran superar ciertas etapas o se producen regresiones, que no recaen sobre la libertad del individuo, sino que están condicionadas por factores ajenos a su responsabilidad.

\subsection{La capacidad para el matrimonio}

El que no se pueda hablar de culpa, repito, no justifica una permisividad absoluta u orientarlos, incluso, hacia comportamientos que no parecen los correctos. La educación en este terreno pretende, como en otros campos, un nivel de integración social que no resulte llamativo. Por eso, tienen derecho a relacionarse con personas del otro sexo, que ayuda a su desarrollo afectivo y sentimental, y evita un aislamiento que no deja de ser peligroso por otras razones. La compañía, el afecto, la amistad heterosexual son factores de equilibrio y estabilidad psicológica, que la mayoría de las veces no causan especiales problemas. Está demostrado quela deficiencia mental no equivale a sujetos hipersexuales o con una sexualidad salvaje y agresiva ${ }^{26}$. Los fallos

25 Catecismo de la Iglesia Católica, nํ2352. En las correcciones efectuadas para la nueva edición oficial, en lugar de «reducen, e incluso anulan la culpabilidad moral». Sin embargo, el Catecismo Católico para adultos II, publicado por la Conferencia Episcopal Alemana, y aprobado por Roma, enseña que el que «haya culpa, y en que medida, en la masturbación depende de si intervine el conocimiento y la libertad. Lo decisivo es si hay voluntad de dar una forma y orientación responsaable a la sexualidad o si domina un egocentrismo culpable», Biblioteca de Autores Cristianos, Madrid 1998, 343. 
podrían deberse más a un fracaso en el sistema educativo que a sus propias limitaciones. Nadie podrá excluir, sin embargo, la posibilidad de cualquier riesgo, como acontece en otras múltiples situaciones de lavida. Aunquefuera necesaria una mayor atención, esto no justificaría el rechazo detales contactos positivos. Son relaciones que evitan la soledad, enriquecen su psicología, desarrollan su mundo afectivo y suponen, por tanto, una mejora en su integración.

A la preguntasobresi un disminuido psíquico estácapacitado para tomar esta opción no se puede responder de forma generalizada. Es matrimonio es una alianza, como la define el Derecho Canónico (c.1055,1), que origina derechos y responsabilidades, y sefundamenta en un consentimiento librey expreso de los contrayentes, que excluye to do lo que gravemente pudiera impedirlo en el ámbito del conocimiento y dela voluntad. La deficiencia o anomalía no siempre supone un impedimento que invalide esta decisión. Sólo el análisis particularizado aportará los datos para sospechar razonablementesi existen las condiciones psicológicas para contraerlo o quedan reducidas con exceso. El Derecho eclesiástico ${ }^{27}$, como también se requiere en el ámbito el civi| ${ }^{28}$, exige un nivel suficiente decapacidad como condición necesaria para su admisión y validez. Lo impide, por tanto, un grave defecto de juicio para valorar lo que significa el consentimiento 0 una imposibilidad de asumir las obligaciones conyugales. Pero ninguna legislación determina más en concreto, fuera de estas generalidades, las diferentes situaciones y matices que pueden encontrarse. Se podría decir que se reducea la imposibilidad psíquica de poder conocer y valorar, con un mínimo de exigencias, los elementos requeridos por el Derecho para esta decisión. Un problema, por otra parte, que no afecta solo a los deficientes psíquicos, ni tienetampoco que darse por tener un nivel de inteligenciainferior.

Como en el mundo jurídico los hechos evidentes no siempre se dan, hay que moverse en las zonas de las presunciones que impiden una seguridad mayor. El único criterio evidente, entonces, es que un derecho fundamental, como el

26 Ver Mạ.L. RAMÓN-LACA, a. c. (n 24).

27 Código del Derecho Canónico, c. 1095, con los comentarios a este canon. Un buen análisis en J.M. DÍAZ MORENO, El Derecho Canónico ante el matrimonio de los deficientes mentales, en AA.VV., o. c. (n. 2), 171-209. F. MELÉNDEZ, Sexualidad y posible matrimonio de las personas con retrasso mental, Sal Terrae 87 (1999) 585-594.

28 Para el Código Civil: Si alguno de los contrayentes estuviera afectado por deficiencias o anomalías psíquicas, se exigirá dictamen médico sobre su actitud para prestar el consentimiento (art. 56,2). F. SÁINZ DE ROBLES, Los deficientes mentales ante la Ley, en AA.VV., o.c. (n. 8), 181-199. L. GONZÁLEZ MORÁN, El Derecho civil ante el matrimonio de los deficientes mentales, en AA.VV., o.c. (n. 2), 143-166. 
compartir la vida con una persona, solo podrá impedirse cuando se tenga la certeza moral de la incapacidad completa de esta persona para comprender lo que realiza. En caso de duda, el derecho ha de prevalecer sobre la posible limitación. Habrá, pues, que estudiar cada caso, con los informes adecuados, para tomar la decisión más benéfica para el paciente.

\subsection{La paternidad responsable: El problema de la esterilización}

La paternidad responsable es una doctrina defendida por la Iglesia, a partir del Vaticano II, y recogida después por los documentos del magisterio ${ }^{29}$. Supone la obligación de no procrear en aquellas condiciones que impiden razonablemente la existencia de un hijo. La primera exigencia sería la de contraer matrimonio, para que el fruto de ese cariño pudiera gozar de un clima estable quefacilitara la educación posterior.

El que una persona disminuida pueda contraer matrimonio, que necesitará, en ocasiones, una cierta ayuda externa para facilitar una buena convivencia, no elimina la responsabilidad dediscernir si, en tales circunstancias, es convenienteo no la descendencia, por el riesgo detransmitir las mismas limitaciones o por las dificultades características que conllevaría su educación. El hijo que va a nacer tiene un hipotético derecho a que su existencia y formación se realiceen las mejores condiciones posibles, aunque no siempresellegue a conseguir ese objetivo. Los datos de un informe genético serán necesarios como ayuda imprescindible para una reflexión objetiva y responsable entre las diferentes posibilidades. Una obligación que afecta también a los padres sanos, pero capaces de transferir taras hereditarias a sus descendientes ${ }^{30}$.

El problema implica de forma directa a todas las personas minusválidas que no hayan contraído matrimonio. Es evidente que, en este caso, la obligación de no procrear es aún mayor. La dificultad se agudiza, cuando son incapaces de comprender las consecuencias de un posibleembarazo y de oponer resistencia a los abusos o solicitaciones de cualquier desaprensivo. Las secuelas para la mujer son también más importantes. Conozco a alguna chica oligofrénica que casi todos los años aparecía por el Clínico con un niño en su seno, al que tenía que abandonar de inmediato. La defensa frente a tales situaciones no resulta eficaz con el recurso a los medios anticonceptivos. Por ello muchos defienden

29 Cf. El don de la vida. Textos del Magisterio de la Iglesia sobre Bioética, BAC, Madrid 1996, donde el índice de materias, pp. 810-811, se hace referencia a los documentos más recientes.

30 De ello he tratado más extensamente en Ética y vida: desafíos actuales, San Pablo, Madrid 1993, 111-124. 
la licitud dela esterilización. ¿Quépensar sobreesta alternativa? ${ }^{31}$.

Las posturas están claramente enfrentadas. Los que niegan, por una parte, su validezética y jurídica, pues setrata deuna mutilación injustificada eimpuesta sin el consentimiento previo del individuo. Es la vulneración de un derecho básico que atenta contra la dignidad de la persona. De ahí que se encontrara sancionada en el Código Penal, incluso cuando el consentimiento haya sido dado por un menor o incapaz, "en cuyo caso no será válido el prestado por éstos ni por sus representantes legales" 32 . Otros creen, sin embargo, que es la única defensa válida para los que no tienen suficiente responsabilidad y están expuestos o pudieran causar embarazos injustificados. Se quería la reforma del artículo citado en la nota anterior para que la esterilización quedara legalizada en algunas circunstancias especiales.

\subsection{La legislación actual}

La ley orgánica del 21 de junio de 1989 aceptó este planteamiento, en un párrafo añadido: "Sin embargo, no será punible la esterilización de persona incapaz que adolezca de grave deficiencia psíquica cuando aquélla hay sido autorizada por el juez a petición del representante legal del incapaz, oído el dictamen de dos especialistas, el Ministerio Fiscal y previa exploración del incapaz" ${ }^{\prime 3}$. Las reacciones se sucedieron de inmediato. Hubo, incluso, un recurso de inconstitucionalidad, presentado por un J uzgado de Barcelona, por considerar que semejante párrafo iría contra los artículos 10, 15 y 49, que defienden los derechos fundamentales de todos los ciudadanos, su integridad física, y el compromiso por atender a los disminuidos físicos o psíquicos. En julio de 1994, una larga sentencia del Tribunal Constitucional concluía queel inciso

31 J.M. DE LAHIDALGA, La procreación eficazmente responsable y los deficientes mentales, Surge 46 (1988), 427-442. Algunos permiten los métodos anticonceptivos, pero no la esterilización. Cf. N. BLÁZQUEZ, Aspectos bioéticos de la demencia, Studium 38 (1998) 425443. Otros mantienen serias dificultades, J . R. FLECHA, La fuente de la vida Manual de Bioética, Sígueme, Salamanca, 272-274.

32 Artículo 428. Era la redacción existente hasta la Ley orgánica del 89, de la que hablaremos después, y que impedía la demanda de esterilización por parte de los padres o tutores.

33 F. BUENO ARÚS, El problema jurídico de la anticoncepción y de la esterilización, en AA.VV., o.c. (n. 8), 201-217, con buena bibliografía. F. C. SÁINZ DE ROBLES, Procreación y deficiencia mental: El problema ético y jurídico de la esterilización de incapaces, en AA.VV., o.c. (n. 2) 213-225. COMISIÓN DE BIOÉTICA EN OBSTETRICIA Y GINECOLOGÍA, Esterilización de personas con deficiencia mentale, SEGO, Madrid 1998, 15-20. Y el coemnatrio al documente en 1âJORNADASDE BIOÉTICA EN OBSTETRICIA Y GINECOLOGÍA, Esterilización de dedficientes mentales, Edtorial Garsi, Madrid 1999, 23-28. 
añadido "no es contrario a la Constitución"34.

Respetand o otras opiniones diferentes, semehacemuy difícil considerar esta opción como éticamente inaceptable, con las condiciones que la misma ley exige. No se trata de una solución que busque la comodidad de los padres o tutores, sin tener ya que preocuparse para nada. Bastantes minusválidos gozan de la autonomía y capacidad suficiente para hacerse responsables de sus acciones, mediante una adecuada educación y la ayuda complementaria que siempre van a necesitar. No estaría justificada una mutilación en estos casos, cuando existen otros recursos que respetan su integridad y defienden con la suficiente garantía de otros peligros. La valoración, sin embargo, podría ser distinta en otras situaciones mucho más complicadas.

No cabe duda que algunas personas están incapacitadas para contraer matrimonio, pero conservan su derecho a relacionarse con otras y mantener relaciones de amistad. En sus circunstancias concretas, la paternidad responsable les obliga a evitar la procreación, ya que no existen las condiciones indispensables para cumplir con ese cometido. Pero la gravedificultad surge, cuando por esas mismas circunstancias no alcanzan un mínimo de responsabilidad frente a las consecuencias de sus acciones o frente a posibles solicitaciones o abusos. Si el minusválido no debe procrear y, al mismo tiempo, es incapaz de cumplir con esa obligación, ya que no puede hacerse responsable desus actos, no veo qué otra salida eficaz pueda ofrecerse. La esterilización será la única defensa posible para evitar otro mal peor. Algo parecido a la mujer normal que se defiende contra las consecuencias de una violación, aunque la esterilidad de una anticonceptivo no tenga el carácter de permanente. La vigilancia continua o el aislamiento social, además de no dar las suficientes garantías, irían contra otras exigencias humanizantes. El peligro deinterpretaciones poco justificadas queda reducido por la intervención del juez, oído el dictamen de los especialistas, el Ministerio Fiscal y la exploración del individuo.

\section{Conclusión}

Alguno ha dicho con humor que la salud es un estado transitorio que no augura nada bueno. Quiero con ello decir que nuestro mundo es un gigantesco hospital en el que todos estamos necesitados de tratamiento. Pero más que progresos técnicos, con los muchos beneficios que nos han aportado, se requiere un avancemucho mayor en humanismo, indispensable parauna salud

34 J.M. DE LAHIDALGA, Esterrilización de deficientes mentales y sentencia del Tribunal Constitucional: reflexión ético-legal 43 (1994) 381-407. 
auténtica, que no afecta exclusivamente al organismo biológico, como ya hemos dicho con anterioridad, sino al conjunto de la persona ${ }^{35}$. La preocupación y el interés por los minusválidos nos obligan todavía más a insistir en esta dimensión, pues sus carencias mayores-delas que otras pueden derivarse- hay que situarlas en el nivel afectivo. Si ellos nos ayudaran a despertar estos sentimientos, tal vez nos daríamos cuenta, entonces, de que no constituyen ningún lastre o peso muerto que se ha de soportar. Al contrario, tendríamos que agradecerles que en nuestra sociedad, tan utilitaria y materialista, ellos nos recuerdan la importancia del cariño y se han hecho fuentes inagotables de ternura. Nuestra respuesta sólo puede ser la admiración, el afecto y la gratitud más profunda. 